\title{
OPTICAL PRoperties OF MDMO-PPV AND MDMO-PPV/ [6,6]-PHENYL C61-BUTYRIC ACID 3- ETHYLTHIOPHENE ESTER THIN FILMS
}

\author{
Bushra Mohamed Omer \\ Department of Applied Physics and Mathematics, Omdurman Ahlia University, \\ Omdurman, Sudan \\ bushra_omer4@yahoo.com
}

\begin{abstract}
Thin films of a conjugated polymer Poly [2-methoxy-5-(3',7'-dimethyloctyloxy)-1,4-phenylenevinylene] (MDMO-PPV) were prepared from chloroform, 1,2dichlorobenzene and toluene solutions by spin coating technique on quartz substrates. Absorption and photoluminescence (PL) spectra of the polymer thin films prepared from different solvents were measured. The UV-vis absorption and PL spectra of MDMO-PPV films was affected by solvents used for spin coating. Further, with Atomic Force Microscope (AFM) it has been demonstrated that the surface morphology of MDMO-PPV: [6,6]-Phenyl C61-butyric Acid 3ethylthiophene Ester thin films depends strongly on preparation condition (solvents).
\end{abstract}

\section{KEYWORDS}

MDMO-PPV, Modified Fullerene, Optical properties, AFM, Thin Films

\section{INTRODUCTION}

Poly[2-methoxy-5-(3',7'-dimethyloctyloxy)-1,4-phenylenevinylene] (MDMO-PPV) is a soluble conjugated polymer and has been used in the fabrication of polymer light emitting diodes [1] and as donor material in the fabrication of bulk-heterojunction photovoltaic cells $[2,3]$. The use of conjugated polymers as active materials in devices has a number of advantages, such as ease of fabrication and low cost. Many parameters may affect the optical properties and surface morphology of the polymer: fullerene bulk-heterojunction solar cells such as the composition between donor and acceptor [4], the solvent used to make blend solutions [5] and the thickness of the active layer [6]. Hoppe et al. investigated the relationship between the nanoscale morphology and the photovoltaic properties of blend films cast from solutions $[7,8]$. Shaheen et al. reported that the morphology of MDMO-PPV: PCBM films are much smoother when spin-coated from chlorobenzene than from toluene [5]. The bulk heterojunction solar cells of the MDMO-PPV: PCBM blend, spin-coated from chlorobenzene instead of toluene led to a threefold increase in the solar cell efficiency. The morphology of the active films in high performance bulk-heterojunction solar cells is characterized by a significantly higher number and smaller size (nanoscale) of the PCBM-rich regions than for the low performance cells [5].

To our knowledge there is no published study on the optical and surface morphology of MDMOPPV: [6,6]-Phenyl C61-butyric Acid 3-ethylthiophene Ester (Modified fullerene) thin films. However, several papers in the literature discussed the effect of thin film preparation condition on the optical and surface morphology of MDMO: [6,6]-Phenyl C61-butyric Acid methyl Ester 
(PCBM) photovoltaic cells $[4,5,7,8]$. In this paper, we report the effect of solvent on the optical properties of the p-type donor polymer MDMO-PPV and on the surface morphology of the thin film of MDMO-PPV: Modified fullerene.

\section{EXPERIMENTS}

\subsection{Optical Measurements}

The p-type donor polymer Poly [2-methoxy-5-(3',7'-dimethyloctyloxy)-1,4-phenylenevinylene] (MDMO-PPV) and the n-type acceptor [6,6]-Phenyl C61-butyric Acid 3-ethylthiophene Ester (modified fullerene) were purchased from sigma-Aldrich Corporation and American Dye Source, Inc. respectively; the chemical structures are shown in Figure 1. All materials were used as received without further purification. For the UV-Vis absorption and photoluminescence (PL) measurements, MDMO-PPV and MDMO-PPV: Modified fullerene films were prepared by using spin coating technique. Chloroform, 1,2dichlorobenzene and toluene were used as solvents; the solutions were spin-coated onto quartz substrates. MDMO-PPV films were prepared at the concentration of $5.20 \mathrm{mg} / \mathrm{ml}, 5.08 \mathrm{mg} / \mathrm{ml}$ and $5.32 \mathrm{mg} / \mathrm{ml}$ of chloroform, 1,2dichlorobenzene and toluene, respectively. The polymer solutions were spin-coated at $2000 \mathrm{rpm}$. The properties of the films were obtained on a Lambda-900 UV/Vis/NIR spectrophotometer (Perkin Elmer) and on LS55 luminescence spectrometer (Perkin Elmer).

\subsection{Sample Preparation for AFM}

MDMO-PPV and modified fullerene were dissolved in chloroform, 1,2dichlorobenzene and toluene to yield a MDMO-PPV: modified fullerene $(3.24: 12.08 \mathrm{mg} / 1 \mathrm{ml}$ chloroform, 3.10:12.37 $\mathrm{mg} / 1 \mathrm{ml} 1,2$ dichlorobenzene and $3.22: 12.88 \mathrm{mg} / 1 \mathrm{ml}$ toluene) solutions. The quartz substrates were cleaned by ultrasonic treatment for 10 minutes using acetone and isopropyl alcohol sequentially. After cleaning of the quartz substrates the solutions were spin-coated at $2000 \mathrm{rpm}$ for 40 seconds. The surface morphology of MDMO-PPV: modified fullerene thin films were studied using atomic force microscopy (CP-II veeco).

(a)

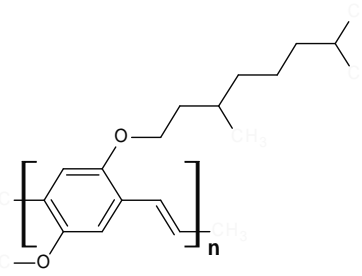

(b)

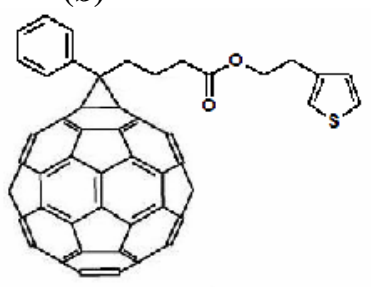

Figure 1. Chemical structure of (a) Poly [2-methoxy-5-(3',7'-dimethyloctyloxy)-1,4-phenylenevinylene] and (b) [6,6]-Phenyl C61-butyric Acid 3-ethylthiophene Ester.

\section{RESULTS AND DISCUSSION}

Figure 2 shows the UV-vis absorption spectra of MDMO-PPV thin films prepared from chloroform, 1,2dichlorobenzene and toluene on quartz substrates. The thin films prepared from 1,2 dichlorobenzene and toluene has approximately the same absorption maximum peaks $\left(\lambda_{\max }\right)$ at $502 \mathrm{~nm}$. The absorption spectrum of the thin film prepared from 1,2dichlorobenzene shows an onset at $591 \mathrm{~nm}$ leading to an optical band gap of $2.10 \mathrm{eV}$. For the thin film prepared from toluene the onset is at $585 \mathrm{~nm}(2.12 \mathrm{eV})$. However, the thin film prepared from chloroform shows a blue shifted absorption maximum peak at $491 \mathrm{~nm}$ and onset at $577 \mathrm{~nm}(2.15 \mathrm{eV})$. The shift in 
the absorption peak can be explained by considering that the conjugation length of the polymer changes in the different solvents. Polymer chains originally in solution are folded and curled in a different way in the different solvents. This morphological state of the chain is in herited in to the film when the solvent is evaporated. The greater the folding and curling of polymer chains is the lesser their conjugation length. All the spectra shows a narrow low intensity peak at $333 \mathrm{~nm}, 345$ $\mathrm{nm}$ and $340 \mathrm{~nm}$ for the films prepared from chloroform, 1,2dichlorobenzene and toluene, respectively.

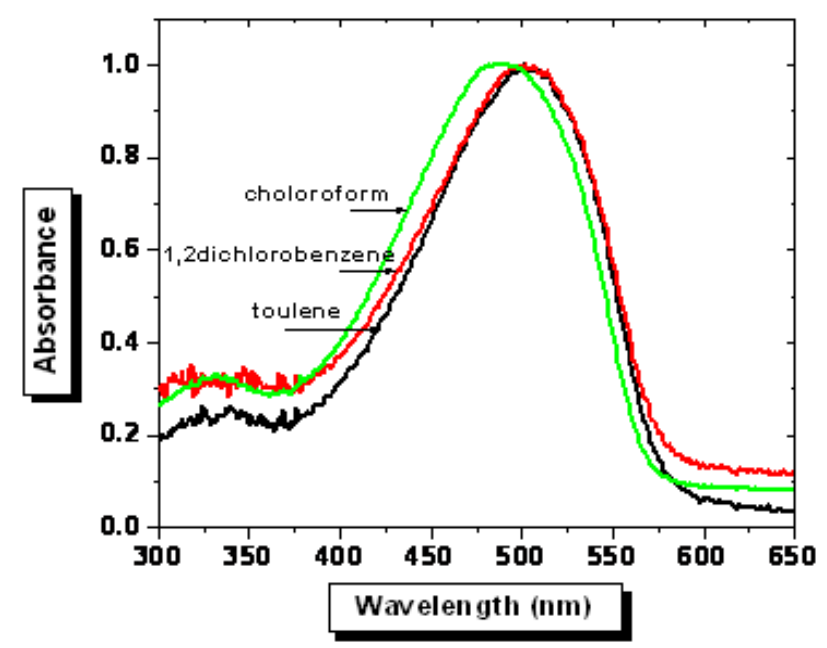

Figure 2. The UV-vis spectra of pure MDMO-PPV film spin-coated from toluene, 1,2dichlorobenzene and chloroform.

in the three different solvents. The PL spectrum of MDMO-PPV thin film prepared from toluene and the one prepared from 1,2dichlorobenzene nearly has the same photoluminescence spectra with a maximum peak at $579 \mathrm{~nm}$. However, for thin film prepared from chloroform the maximum peak is red-shifted by more than $20 \mathrm{~nm}$ and appear at $600 \mathrm{~nm}$. The shift in PL may attribute to formation of aggregates, which is solvent dependent. Absorption and photoluminescence data for MDMO-PPV thin films are summarized in Table 1. Significant changes into the values of Stokes shift related with solvent used in thin films preparation was observed. The reason of the different in Stokes shift is due to polymer/solvent interaction through the solvent's optical parameters (refractive index and dielectric constant), it may also related to the magnitude of the change of dipole moment of the electronic ground state and the excited state. The PL spectra in all the cases Figure 3 shows the photoluminescence (PL) emission spectra of MDMO-PPV thin films prepared are red shifted with respect to absorption spectra. 


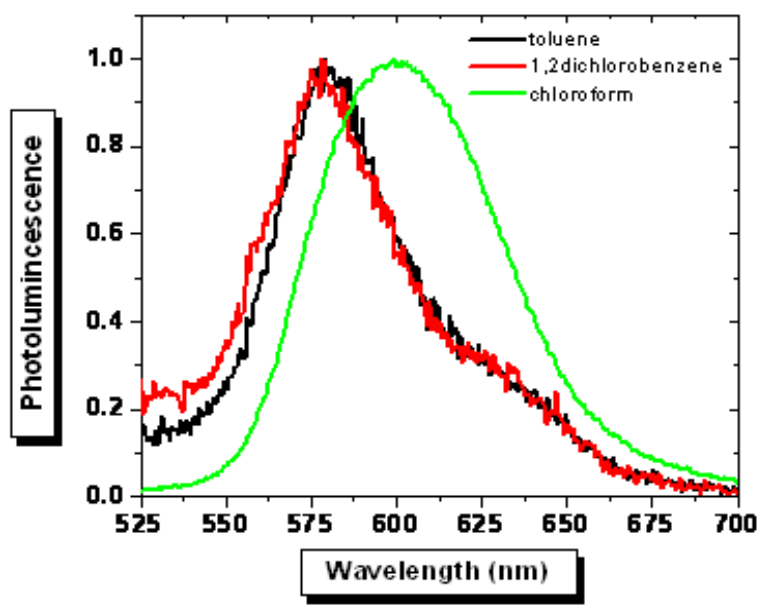

Figure 3. The PL spectra of pure MDMO-PPV film spin-coated from toluene, 1,2dichlorobenzene and chloroform.

Table 1. Optical Data of MDMO-PPV in thin films spin-coated from different solvents.

\begin{tabular}{|l|l|l|l|l|l|}
\hline Solvent & $\begin{array}{l}\lambda_{\text {max }}, \mathbf{U V} \\
(\mathbf{n m})\end{array}$ & $\begin{array}{l}\lambda_{\text {onset }} \\
(\mathbf{n m})\end{array}$ & $\begin{array}{l}\lambda_{\text {max }}, \mathbf{P L} \\
(\mathbf{n m})\end{array}$ & $\begin{array}{l}\text { Stokes shift } \\
(\mathbf{n m})\end{array}$ & $E_{g}^{\circ \text { \%t }}(\mathbf{e V})$ \\
\hline chloroform & 491 & 577 & 600 & 109 & 2.15 \\
\hline 1,2dichlorobenzene & 502 & 591 & 578 & 76 & 2.10 \\
\hline toluene & 501 & 585 & 579 & 78 & 2.12 \\
\hline
\end{tabular}

Figure 4 shows the UV-vis absorption spectrum of a thin film of [6,6]-Phenyl C61-butyric Acid 3-ethylthiophene Ester. Two peaks appear at 266 and $336 \mathrm{~nm}$ and there is abroad tail of absorption extended to as long as $800 \mathrm{~nm}$. Figure 5 shows the absorption spectra of MDMO-PPV: Modified fullerene (1:4) thin film spin-coated from 1,2dichlorobenzene. The addition of modified fullerene modifies the absorption properties of the composites. The peaks at $267 \mathrm{~nm}, 337 \mathrm{~nm}$ arise from the modified fullerene and the one at $482 \mathrm{~nm}$ arise from MDMO-PPV. The onset wavelength of the blend is at $607 \mathrm{~nm}(2.04 \mathrm{eV})$, blue shifted by $16 \mathrm{~nm}$ compared to the onset absorption of MDMO-PPV. The spectrum is a superposition of the two components. There is no indication of states below $\pi-\pi^{*}$ gap of the conjugated polymer that might arise from ground state interactions such as doping. 


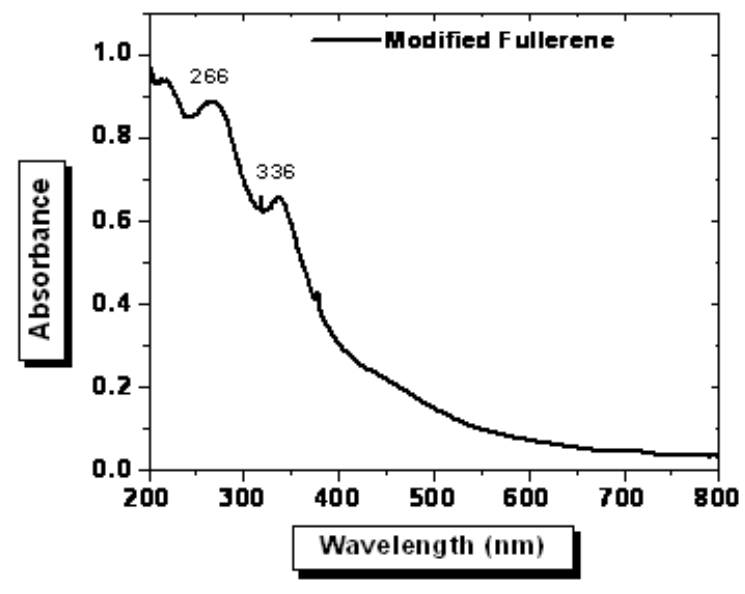

Figure 4.Optical absorption of pure Modified Fullerene film spin-coated from chloroform.

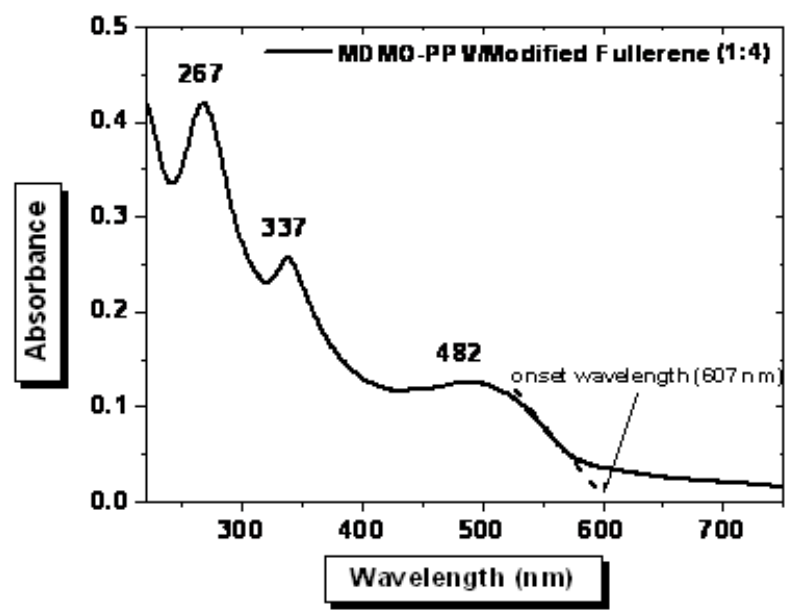

Figure 5. Optical absorption of MDMO-PPV: Modified Fullerene (1:4) film spin-coated from 1, 2diclorobenzene.

Figure 6 shows AFM images of the surfaces of MDMO-PPV: Modified fullerene (1:4) blend films prepared from different solvents. The images clearly show different surface morphologies. For MDMO-PPV: Modified fullerene film fabricated from chloroform, the area roughness is 7.43 $\mathrm{nm}$ and the average height is $30.24 \mathrm{~nm}$ (Figure 6.a). The surface of the chloroform coated film contains features with horizontal dimensions on the order of $0.3 \mathrm{~m}$. The film fabricated from 1,2 dichlorobenzene has a surface with area roughness of $6.99 \mathrm{~nm}$ and average height of $28.51 \mathrm{~nm}$ (Figure 6.b). The 1,2dichlorobenzene coated film contains structures with horizontal dimensions less than $0.2 \mathrm{~m}$. In Figure 6.c the thin film prepared from toluene shows the rougher surface with area roughness of $22.66 \mathrm{~nm}$ and average height of $68.85 \mathrm{~nm}$. From AFM images it was clear that the thin film prepared from 1,2dichlorobenzene shows much more homogeneous mixing of the photoactive layer in combination with a smoother surface. The film obtained using a toluene solvent led to larger phase-separated regions than when 1,2dichlorobenzene or chloroform was used. 
(a)
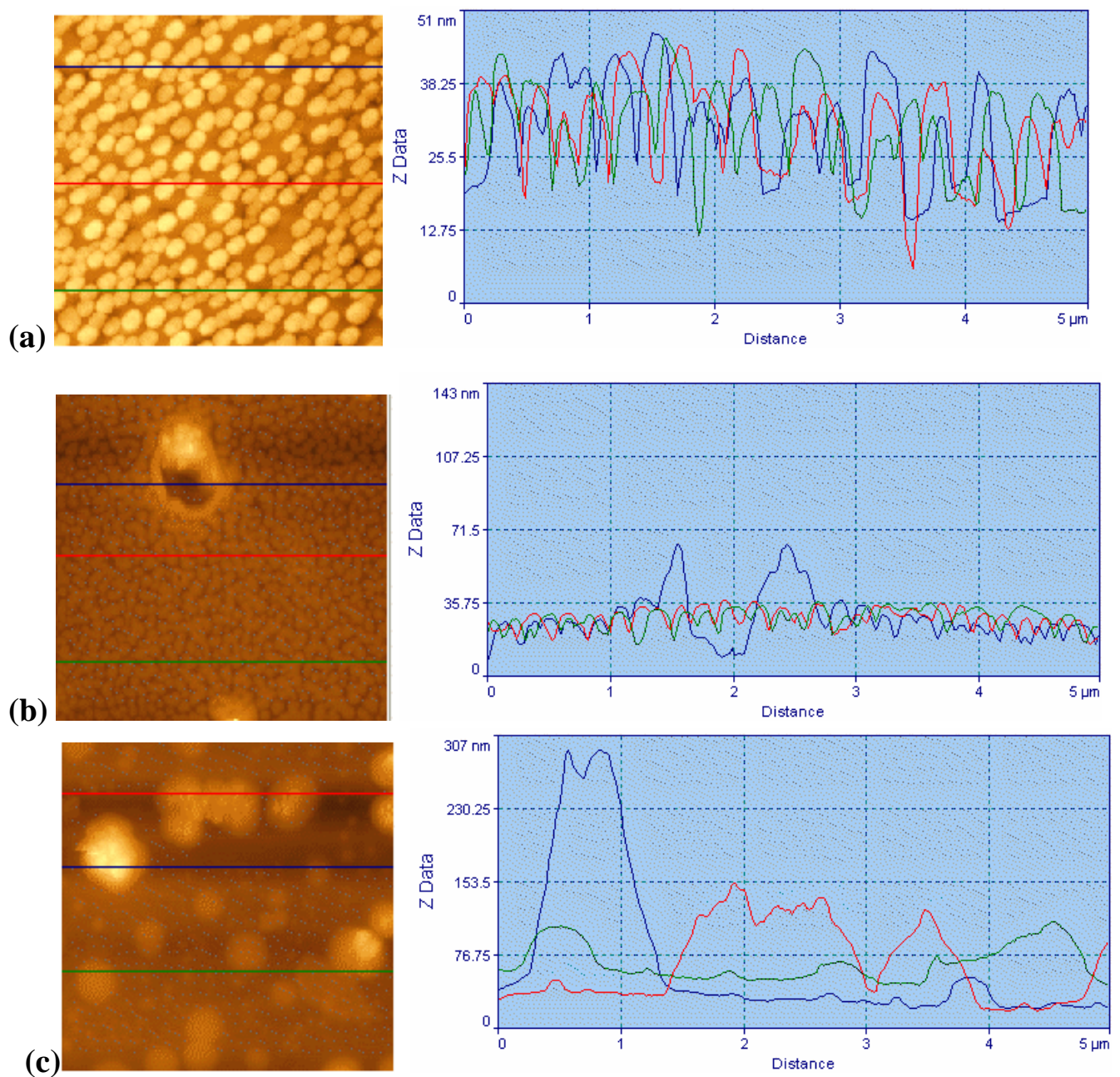

Figure 6. AFM images (5 x $5 \mathrm{~m} 2)$ of (1:4) MDMO-PPV: Modified fullerene films spin-coated from (a) chloroform on quartz substrate (area roughness $=7.43 \mathrm{~nm}$ and average height $=30.24 \mathrm{~nm}$ ).

(b) 1 ,2dichlorobenzene on quartz substrate (area roughness $=6.99 \mathrm{~nm}$ and average height $=28.51$ $\mathrm{nm})$.

(c) toluene on quartz substrate (area roughness $=22.66 \mathrm{~nm}$ and average height $=68.85 \mathrm{~nm}$ ).

\section{Conclusions}

In conclusion, we have studied the effect of solvent on the optical properties of MDMO-PPV films and on the surface morphology of MDMO-PPV: modified fullerene films. We have shown that by varying the solvent used for polymer: modified fullerene spin coating, we can alter the thin film morphology. For MDMO-PPV: modified fullerene, the thin film prepared from 1,2 dichlorobenzene show the smoother surface, while the thin film prepared from toluene shows the rougher surface.

\section{ACKNOWLEDGEMENTS}

Author is grateful to the school of Applied physics and the Institute of Microengineering and Nanoelectronics (IMEN), University of Kebangsaan Malaysia for unlimited support. 


\section{REFERENCES}

[1] P.W.M.Blom \& M.J.M.DE JONG, (1998) "Device Operation of Polymer Light-Emitting Diodes", Philips J.Res., Vol. 51, pp 479-494.

[2] Sean E.Shaheen, Rachel Radspinner, Nasser Peyghambarian, Ghassan E.Jabour, (2001) "Fabrication of bulk heterojunction plastics solar cells by screen printing”, Appl. Phys. Lett.,Vol. 79, No. 18, pp 2996-2998.

[3] Floris B.Kooistra, Valentin D.Mihailetchi, Lacramioara M. Popescu, David Kronholm, Paul W. M. Blom, \& Jan C. Hummelen, (2006) "New C84 Derivatives and Its Application in a Bulk Heterojunction Solar Cell”, Chem. Mater., Vol. 18, pp 3068-3073.

[4] Jeroen K.J. van Duren, Xiaoniu Yang, Joachim Loos, Corrie W.T.Bulle-Lieuwma, Alexander B. Sieval, Jan C.Hummelen, Rene A.J.Janssen, (2004) "Relating the Morphology of Poly(p-phenylene vinylene)/ Methanofullerene Blends to Solar-Cell Performance”,Adv. Funct. Mater.,Vol. 14, No. 5, pp 425-434.

[5] Sean E.Shaheen, Christoph J.Brabec, N.Serdar Sariciftci, Franz Padinger, Thomas Frromherz, Jan C. Hummelen, (2001) "2.5\% efficient organic plastic solar cells”, Appl. Phys. Lett., Vol. 78, No. 6, pp 841-843.

[6] M.Lens, L.J.A.Koster, V.D.Mihailetchi, P.W.M.Blom, (2006) "Thickness dependence of the efficiency of polymer: fullerene bulk heterojunction solar cells”, Appl. Phys. Lett., Vol. 88, pp 243502-243505.

[7] Hoppe, Michael Niggeman, Christoph Winder, Jurgen Kraut, Renate Hiesgen, Andreas Hinsch, Dieter Meissner, Niyazi Serdar Sariciftci, (2004) "Nanoscale Morphology of Conjugated Polymer/Fullerene-Based Bulk-Heterojunction Solar Cells”, Adv. Funct. Mater., Vol. 14, No. 10, pp 1005-1011.

[8] Harald Hoppe, Niyazi Serdar Sariciftci, (2006) "Morphology of Polymer/Fullerene bulk heterojnction solar cells”, J. Mater. Chem., Vol. 16, pp 45-61.

\section{AUTHOR}

Bushra Mohamed Omer. Received the B.Sc. in Applied Physics \& Mathematics from Omdurman Ahlia University (OAU) in 2000. Received the M.Sc and Ph.D. in Physics from University of Khartoum in 2005 and 2011, respectively. In 2011 appointed as Assistant Professor at the Department of Applied Physics \& Mathematics, OAU. Main research activities are in the field of organic optoelectronics with a special focus on organic solar cells.

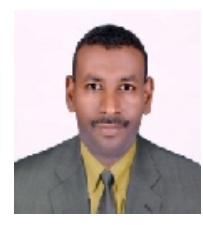

